\title{
Erratum to: Metabolic syndrome and all-cause mortality: a meta-analysis of prospective cohort studies
}

\author{
Sheng Hui Wu $\cdot$ Zhong Liu $\cdot$ Suzanne C. Ho
}

Published online: 11 August 2010

(C) Springer Science+Business Media B.V. 2010

Erratum to: Eur J Epidemiol (2010) 25:375-384

DOI 10.1007/s10654-010-9459-z

Unfortunately, one of the co-author's name has been misspelled both in online and print publication of the original article as "Wu Sheng Hui". The correct name is Sheng Hui Wu.

The online version of the original article can be found under doi:10.1007/s10654-010-9459-z.

\section{S. H. Wu}

School of Public Health and Primary Care, The Chinese

University of Hong Kong, Shatin, NT, Hong Kong SAR,

People's Republic of China

e-mail: shenghuiwu@cuhk.edu.hk

S. H. Wu

Nanjing Maternal and Child Health Care Hospital,

Nanjing City, People's Republic of China

Z. Liu

Department of Orthopaedics and Traumatology, The Chinese

University of Hong Kong, Shatin, NT, Hong Kong SAR,

People's Republic of China

e-mail: 1zh93@hotmail.com

\section{Z. Liu}

School of Basic Medical Science, Southeast University,

Nanjing, People's Republic of China

S. C. Ho $(\bowtie)$

4/F, School of Public Health and Primary Care, The Chinese University of Hong Kong, Prince of Wales Hospital, Shatin, NT,

Hong Kong SAR, People's Republic of China

e-mail: suzanneho@cuhk.edu.h 